\title{
'Changing the Mix': Contestation Surrounding the Public Housing Stock Transfer Process in Victoria, New South Wales and Tasmania
}

\author{
KEITH JACOBS*, GREG MARSTON† and MICHAEL DARCY $\ddagger$ \\ *School of Sociology, Social Work and Tourism, University of Tasmania, Hobart, Australia \\ tSchool of Social Work and Applied Human Sciences, University of Queensland, Australia \\ ‡College of Social and Health Sciences, University of Western Sydney, Australia
}

\begin{abstract}
This article presents the findings of a study examining the rationale and practices of stock transfer from state housing authorities to community housing associations in three Australian states-Victoria, New South Wales and Tasmania. It begins with an analysis of the policy context that has informed debates about housing management and supply options in Australia. The main section of the article draws on written documentation and interviews with policy actors and tenants in each of the case studies to highlight the conflicts and tensions that surface in moves to reconfigure the management of public housing. Alongside a brief discussion about the policy themes that emerge from the findings, it is suggested in the conclusion that the continuing contestation and uncertainty about the stock transfer process is symptomatic of the national 'policy vacuum' about the future direction of public housing in Australia.
\end{abstract}

KEY WORDS: community housing associations, stock transfer process, public housing

\section{Introduction}

In Australia, there is a paucity of research examining the role of non-government agencies in the management of housing services. There is also very little research that places the relationship between public, private and non-profit housing providers in a broader mixed economy of welfare context. Yet, the developments taking place within contemporary housing policy stem from a set of processes that have affected welfare provision not just in Australia but also in Europe and North America (see Cahill, 1994). These include governments' willingness to impose controls on the availability of resources for welfare provision, support for private sector agencies to undertake many of the activities formerly associated with direct state provision and the focus on individual responsibility and self-help in discourses about the future of welfare. For example, the endorse-

Correspondence Address: Dr Keith Jacobs, Private Bag 17, University of Tasmania, Hobart, TAS 7001, Australia. Fax: + 61 (0)3 6226 2279; Tel.: + 61 (0)3 6226 2928; Email: keith.Jacobs@utas.edu.au 
ment of 'self-help' is implicit in the current Commonwealth State Housing Agreement in the section that contains a new focus on securing employment opportunities for public tenants (Family and Community Services [FACS], 2003, p. 22).

The orthodox view is that those nation-states that maintain tight fiscal control and stimulate private sector activity and civic responsibility are most likely to secure economic benefits. A fundamental restructuring of the welfare state is seen as a necessary course of action by most governments in the developed world. One of the clearest examples of this restructuring is provided by recent developments in the management and ownership of public housing (i.e. budgetary constraints, public and private sector partnerships and stock diversification programs).

\section{The Policy Context}

In recent years, public housing has become a residualised tenure in Australia's housing system with as many as 90 per cent of the 346000 households in public housing relying on income support. As many as two-thirds of these tenants are aged and disability support pensioners (Productivity Commission, 2004). In 2003, a Commonwealth State Housing Agreement (CSHA) for the period 20032008 was finalised under which state housing authorities (SHAs) are expected to establish new partnerships with private and non-profit sectors to secure additional investment for the housing stock. There is also an expectation within the current CSHA that SHAs should seek to extend 'consumer choice', tenant participation, employment and capacity building opportunities by supporting alternative smaller housing providers such as community housing associations (FACS, 2003).

A major driver of housing policy has been declining funding for public housing. For example, government assistance for public housing provided through the auspices of the CSHA has declined in real funding terms by almost 15 per cent between 1990 and 2000 (Steering Committee for the Review of Commonwealth/State Service Provision, 2000, p. 1357). The reduction of funds has placed significant pressure on SHAs to establish 'alternative' forms of housing provision either in the private sector or through the non-profit sector as a way of ultimately circumventing this shortfall of funds. An efficiently managed community housing sector is seen as the basis for attracting private investment to drive the growth of social housing. However, as the case studies show, there is no clear consensus about the best way to implement such a strategy, and no evidence or indication that it will result in more social housing being provided for a reduced or even the same outlay.

The rationale underlying the growth of community housing is that multiple providers increase the choices available to tenants as 'consumers', and to government as the 'purchaser' of social housing services, and that choice in turn results in outcomes more tailored to the individual needs of applicants (see Mant, 1992; National Housing Strategy, 1992; Industry Commission, 1993; Darcy, 1996). It is also the case that the growth of long-term community housing has been driven by a programmatic response on the part of successive Federal and State governments (through initiatives such as the CSHA Community Housing Program), in conjunction with community-based initiatives. It has been argued that the growth of community housing has taken place because of 'top-down' 
processes and from the impetus set in place by the community sector itself (Darcy, 1999; Farrar et al., 2003). Despite these developments occurring over the last 20-30 years the long-term community housing sector still only represents about 1 per cent of total housing stock in Australia.

New policies and practices in the social housing sector have in the past, and are likely to continue to draw on models developed in the UK to encourage private sector and non-government agencies to manage and maintain public sector housing. Voluntary transfers of municipal stock, discounts for tenants to buy their council property, alongside extra resources for housing associations have been a feature of UK social housing for a considerable period (see Jacobs, 1999; Malpass \& Mullins, 2002). Since 1988, 118 municipal landlords (local authorities) have transferred nearly 600000 homes to housing associations (registered social landlords) under the Large Scale Voluntary Transfer (LSVT) and the Estates Renewal Challenge Fund (ERCF) (National Audit Office, 2001). In the UK, there have been closely related developments in allocation practices across multiple providers involving not only common registers, but also 'nomination rights' for the transferring authorities (Clapham \& Kintrea, 1994; Murie, 1995). Tenants also have the option to veto stock transfer proposals through a ballot (Malpass, 2000; Malpass \& Mullins, 2002). On some London estates and in Birmingham, tenant activist campaigns calling for tenants to reject stock transfer proposals were successful. The examples of stock transfer in the UK context provide useful information about what sort of regulatory framework is appropriate in Australia and the difficulties that can arise when tenants organise to oppose the transfer of stock. A number of states and territories are in the process of developing regulatory frameworks for the community housing sector. These governance questions concern the principles of accountability and transparency and the sorts of relations that are appropriate between government and community organisations.

\section{Case Studies}

The empirical research for this article was undertaken in late 2003 and entailed the following tasks: collecting data on current practices and policies in relation to stock transfer in the three states; 30 interviews with key actors working for SHAs and community housing organisations (10 per case study); and three focus group discussions (one in each case study) with tenants to ascertain their expectations and experiences of public and community housing (24 tenants in total). The following sections report on the key findings.

\section{Victoria}

Community housing in Victoria represents less than 1 per cent of total housing stock, while public housing constitutes about 4 per cent. In terms of the social housing sector alone, community housing represents about 8 per cent of all social housing dwellings (AIHW, 2003). These figures indicate that community housing is a relatively marginal tenure in the housing system, yet it fulfils an important function for many low-income households. Victoria has around 7500 units $^{1}$ of housing that are either owned or managed by local government and community housing organisations. Currently, there are about 9000 households assisted by community housing in Victoria. Most of the community housing 
stock has been acquired through capital grants provided through the CSHA, however, there are also a number of joint ventures in operation. In terms of stock profile, Victoria only has around 600 properties that are head-leased (AIHW, 2003).

Controversy and contestation. From the outset it is important to note that stock transfers from public to community housing is one of the most contentious issues in Victorian housing policy discourse. A representative from a peak community housing provider in Victoria argued that:

stock transfers are probably the crunch issue because whilst there is this theoretical desire to grow these associations, certainly there's a lack of capital dollars around to do that. So one of the suggested ways to acquire properties was to transfer them across. I admit that that's controversial, and how do you hand over what is a public asset to a community organisation, which is I guess the driving force behind regulation.

Further evidence about the contested nature of stock transfers can be found in the publication of the Social Housing Innovations Project (SHIP) in 2000. The SHIP report was commissioned by the Office of Housing, Department of Human Services and was authored by Hal Bisset (2000). The SHIP, which fell under the State government's broader Social Housing Program initiative, provides a useful exemplar of the arguments that are raised for and against stock transfers. Bisset's consultancy report was commissioned to seek out innovative affordable housing solutions, look at funding models for successful projects elsewhere, and assess these solutions and make recommendations. The report was written against a backdrop of decreasing supply of affordable rental housing in the private rental market and increasing demand for affordable housing.

The SHIP report was accompanied by $\$ 94.5$ million worth of State government funding, which involved seeking expressions of interest from organisations such as churches and community groups to develop innovative housing projects. ${ }^{2}$ More recently, the Victorian government has announced a commitment to commence the development of four new Affordable Housing Associations, to expand housing for older Victorians, people with a disability, and in designated regional areas. These initiatives were spurred on by the ideas contained in the SHIP report.

In broad terms, the SHIP report sought to build widespread support for community housing and it contained a number of recommendations that favoured the development of community housing through the growth of housing associations. Bisset (2000, p. 18) defines a housing association as a "not-for-profit community organisation with capacity to develop, own and manage social housing". The report recommended that one strategy for pursuing the development of housing associations could be through the transfer of about 18000 of the state's 66000 public housing properties to 20 new housing associations. The release of the report, and this recommendation in particular, created a great deal of controversy in the media and among community sector organisations and public tenant advocates. The Housing for the Aged Action Group (HAAG), for example, ran a public campaign under the slogan: "Sink the S.H.I.P campaign". The campaign was based on continuing support for public housing and a desire to avoid competition between public and community in a policy environment 
driven by limited capital expenditure, an ageing public housing stock portfolio and a shrinking supply of affordable housing in the private rental market.

There were also concerns expressed by tenant advocates about accountability arrangements and allocation and eligibility policies. The HAAG argued that the public system does work and that the SHIP report represented "... an attempt by vested interests to wrest control of a substantial proportion of public housing" (HAAG, 2001). Other concerns raised by tenant advocates were that the transfer would lead to a more residualised public housing system, erode tenants rights and would jeopardise affordability (Melbourne Times, 22 August 2001). In 2001, The Age and The Melbourne Times ran a series of articles that echoed the divided views about large-scale stock transfers. Kenneth Davidson, a staff columnist, wrote an opinion piece in The Age (16 August 2001), where he criticised the proposal as transferring public assets into private hands.

What was at stake in this debate is whether the provision of affordable, accessible and appropriate housing is a public or private responsibility? Some tenant advocates in Victoria are keen to cast community housing as private provision, yet many community housing providers see themselves as occupying a 'third space', between the market and the government. A representative from a large community housing provider in Victoria stated that non-government organisations need to be seen differently to private for-profit organisations:

I mean the basis of the Ken Davidson article was that he went the whole hog. He crossed over directly from public sector to private sector missing in one full swoop the NGO component, which is a pretty critical one.

Whether stock transfers is a subtle form of privatisation or a distinctive sphere of operation mediating the relationship between citizens and governments remains a very controversial and sensitive issue in Victoria, particularly given the recent history of privatisation in Victoria under the Kennett Government.

A need for clarity. In part, the debate concerning tenants' rights and the appropriate level of private sector funds set out above, reflect a need for bold political leadership to articulate the definition of the policy problem and the proposed solutions. The need for more clarity about the future of social housing was a common interview theme raised by providers, tenant advocates and tenants. As one tenant said:

so at the moment there's no clarity of what rent setting would look like, there's no clarity around securing a tenure issue, there's no clarity around access ... is it a common waiting list, is it a single purpose waiting list, what does that look like?

Some of the tenant advocates were critical of the lack of direction and openness about the future of public and community housing in Victoria:

basically the problem is that a lot of the discussion has occurred 'confidentially', and so things have been put on the table but nobody actually knows what the firm policy is. So whilst stock transfer is something that's been talked about, in Victoria at least, there's no stated policy. 
In an effort to increase clarity there was a desire by tenant advocates to have a policy framework in place for making these sorts of decisions, a policy framework that puts tenant outcomes first: "We need mandated outcomes so we've got some certainty and safety." The sorts of mandated outcomes that were discussed in the interviews included affordability, accessibility, appropriateness, tenure security, housing standards, participation structures, dispute resolution and amenity. These outcomes were discussed in the context of an appropriate regulatory framework for community housing in Victoria. There was a concern expressed that 'system needs' such as financial viability, stock profiling and infrastructure should not take on "a life of their own", without any clear commitment to tenant outcomes.

While everyone wanted to see these ideas developed and discussed there was also cynicism expressed about the possibility of this happening in the near future. There was a sense in which the politics of policy making and the contest between different interests was getting in the way of setting clear directions, as indicated by a representative from a peak community housing provider: "To me that's why things just ground to a halt you know, instead of working cooperatively and in goodwill." One community housing provider felt that there needed to be a clear financial game plan in order to move things forward in Victoria:

It's not about community housing management versus public housing management. It's all about finance. They either are going to transfer stock which needs major modification or upgrade, and they don't have the money to do that, or else if they're going to transfer stock which provides a basis ... a financing basis to construct in growth supply. So I don't think the [community] sector should be naive about what the aims and intentions are, and I don't think there are bad intentions. So that's the first thing. The second thing is the requirement of the community housing sector to lead a proper consultation process, it should present its best face to the tenants and develop its own social contract with the tenants ... we shouldn't require the public housing authority to make all the moves.

This last part of the above excerpt draws attention to the dilemma of stock transfer in the context of a community housing sector that is in part a direct consequence of programmatic funding and tax measures provided by government. The sector wants to represent itself as different to government provision, yet at the same time it is highly dependent on all levels of government for its capital and recurrent funding. Advocates for community housing seek to provide locally responsive, participatory forms of housing provision. Yet at the same time, the sector remains highly dependent on government support, which some advocates argue undermines the capacity for flexibility, innovation and autonomy.

The other challenge is that expanding 'third sector' forms of service provision through stock transfers has little impact on either the dominance of the market or the shrinking role of the state, or what Gilbert (2002) refers to as the 'silent surrender of public responsibility'. Some interviewees expressed a concern that stock transfers from public to community housing may do little more than shift deck chairs, while failing to address the structural problems of limited supply and increasing unaffordability. As one tenant advocate stated: "There's 
no suggestion that even housing associations are going to deal with the housing crisis because the amount of extra stock they might create is minimal."

Despite the recommendations of the SHIP report and the announcements of the government to develop growth housing associations, there has been no large-scale stock transfer in Victoria and there is no clear government position on whether this will happen in the future. At the time of writing, it remains unclear whether large-scale stock transfer will be a part of the funding strategy for the government's election commitment to develop the four growth housing associations.

\section{New South Wales}

In New South Wales (NSW), of around 140000 social housing dwellings (approximately 6 per cent of total housing stock), housing associations and co-operatives account for about 9000 dwellings. While still a relatively small sector, this represents an increase of more than 250 per cent since 1995. Close to one-third of this growth has been achieved through the transfer of the management of properties from the SHA mainly to a small number of housing associations termed 'growth associations'. It is important to note that in NSW housing associations do not hold freehold title to these dwellings. The bulk of their stock is leased on the private market for sub-letting to tenants, while so-called 'transferred' stock, while managed by associations, remains the property of the State Land and Housing Corporation (L\&HC).

Policy history. Since the mid-1990s the Department of Housing (DoH) has made clear its intentions to use this limited form of stock transfer as a strategy to address management problems on large estates, and also to stimulate innovation and improved efficiency in the broader social housing sector (NSW Department of Housing, 1999). Following the announcement that 900 properties would be transferred to the 17 housing associations identified for growth across NSW by July 1999, protocols were developed to govern the transfers. The protocol focused on ensuring a 'consistent framework to develop appropriate strategies for determining the location, nature and timing of property transfers' and is largely concerned with financial and administrative arrangements between Office of Community Housing $(\mathrm{OCH})$ and $\mathrm{DoH}$.

In line with the focus of the protocol, early transfers consisted almost exclusively of vacant properties in line with the focus of the protocol. In the push to achieve targets up to 10 per cent of the units identified for transfer were tenanted at the time, and many of these tenants ultimately transferred their leases to housing associations (Darcy, 1999; Darcy \& Stringfellow, 2001). Despite the fact that legal title to the properties remains with the L\&HC, the protocol stated that properties should ideally be separately titled or capable of separate title (NSW Department of Housing and Office of Community Housing, 1997). This would have the effect either of discounting a large number of properties from being transferred or of ensuring that dwellings would mainly be transferred as whole blocks, streets or even estates since a considerable number of $\mathrm{DoH}$ properties are on 'superlots' (large subdivisions of land) and individual dwellings are not on separate titles. 
Renewed interest. Following this initial period, there was little transfer activity in the state until 2003 when funds were set aside for a program of 1000 transfers in the current budget year. It was reported by interviewees that these would be transfers of tenanted properties. Nonetheless, in recent years individual housing associations have taken on management of a substantial number ("some hundreds" according to one interviewee) of new properties constructed in the course of redevelopment of old public housing areas-in these cases, housing associations have been invited to submit expressions of interest in managing stock and the State Authority has retained nomination rights for an agreed proportion of allocations, although one senior DoH interviewee told us "that's atrophied ... that doesn't happen".

A number of interviewees indicated that they believe that the State Authority is developing plans to rapidly accelerate the transfer program through either or both of two initiatives:

- a mass transfer of 1000-2000 units to one existing large housing association, and/or

- the creation of a new autonomous entity, from an existing unit of the DoH, with management of up to 2000 units.

One housing association interviewee spoke of plans to transfer up to 10000 units. It should be pointed out that although there are no formal policy documents available to support this contention, it appears to be widely accepted. Certainly all of the DoH operational managers and housing association peak organisation staff who participated in interviews believed that transfers would be significant over the next 5 years.

Contradictory perceptions. Thus, current plans to revisit stock transfer, announced or rumoured, were of considerable interest for those interviewed for this project. However, based on an analysis of their responses, there is little consensus as to the reasons for pursuing such a policy as the means of expanding community housing. Contradictions and confusion are apparent, not just between the understanding and perception of different policy players, but within the responses provided by even the most experienced and centrally placed respondents.

DoH operational managers see the renewed policy interest in transfers in very positive terms, and along with other interviewees, referred broadly to the need for housing associations to grow in order to achieve management economies. This group, however, consistently referred to the fact that housing association tenants are eligible for Commonwealth Rent Assistance (CRA), and thus having a greater proportion of tenants in community housing would produce a larger income stream for social housing in general. They saw this as a key policy driver, despite the fact that associations do not receive CRA as rent, but merely assess it as income, meaning that only 25 per cent comes back into the system.

Housing association managers were much more likely to refer to the possibility of gearing new finance into the system through secured debts, but took the opportunity to stress that this would not be possible unless associations were given mortgageable title to property. Housing association managers were more circumspect about the prospects of a renewed push for larger scale transfers and referred to past experience where they felt that they had little 
influence over stock selection in terms of location or condition-they referred to the additional costs of managing housing on large estates

not just collecting the rent and doing repairs and maintenance, but actually looking at the social issues within housing estates is far more labour intensive... The Department of Housing is not enforcing the nomination rights, ... it could be quite disastrous for us if on a hundred of the three hundred houses we have the Department had nomination rights.

Not surprisingly, DoH operational managers took quite a different viewthey saw transfers on large estates as being central to the aims of the program, not only as a way of diversifying management on estates, but also as a means of equalising the standard of housing between Associations and the Department: "if Housing Associations don't take transfers (in estates) then ... they would end up with less overall but probably better quality housing ... it will further stigmatise Public Housing as the absolute last resort".

Housing association managers also referred to the lower pay and working conditions they were able to provide. In turn, this suggests that it is almost impossible for Associations to attract and retain staff with sufficient training or skills in community development to work effectively in the estate environment. Policy making and the process of selection to adjudicate which Associations are to receive transfers of public housing appear to lack transparency "there's a panel apparently ... It's a sort of mysterious panel." When asked what the reasons might be for promoting transfers as the means of growing the Association sector, there was a strong sense of this practice being imposed on housing associations. Community housing managers said "It's a government policy-ask the government!" "I really don't know-I suspect it's because we pay people less" ... "I can't see any real advantage" and "trying to read between the lines, maybe its cost" "it's the only idea they've got in there isn't it". Yet all stated they would continue to accept them "because politically its bad news to say no". A housing manager from an organisation that had previously taken a policy decision not to accept transfers because "we would have had to take them in an area that we didn't consider ours... we're very much of the belief that Housing Associations should be local", said that they would probably begin seeking them because there would be no other capacity for growth in the future.

Many other areas of philosophical and policy divergence are apparent in the interview data. These include: an emphasis on smallness as a key factor in the ability of Associations to deliver high quality tenant management versus the notion that only large increases in stock under management can provide viability; a consistent contention that it is Associations and the State Authority working alongside each other "competing" which generates innovation and responsiveness, set alongside the view that a single provider would be more cost effective in regional areas; and tension between the idea of flexibility and the need for common standards and policies, shared allocation processes, etc. in the name of equity.

\section{Tasmania}

Discussions about stock transfers in Tasmania have had a long gestation period. The interview data reveal divergent perspectives but also areas of substantive 
agreement amongst the range of key actors (tenants, housing associations, peak bodies and the SHA). There are currently 12066 public housing dwellings and 456 community housing dwellings in Tasmania. The largest community housing association is Red Shield (managed by the Salvation Army) and the primary association to have negotiated the transfer of public stock. This transfer commenced in 1998 when 120 empty public housing properties were handed over for Red Shield to manage. As part of this agreement, the State government provided $\$ 50000$ as seed funding (Donoghue, 2001). While the properties were vacant at the time of transfer, as many as 40 new occupants were former tenants of the SHA. The only other stock transfer to have taken place was five properties handed over to Devon District Housing Cooperative.

In retrospect, the transfer of stock that took place in 1998 can be viewed as the culmination of detailed policy deliberation and extensive consultation with the community sector. Recently, the State government has reinvigorated policy discussion on the scope of stock transfers following the launch of the 'Affordable Housing Strategy' in early 2003. Despite the small number of properties that have been transferred to date, there is an expectation that the transfer of more stock to community housing associations might enable the State government to leverage Commonwealth Rental Assistance funds. ${ }^{3}$

The arguments for and against stock transfer as a policy instrument for social housing provision have already been touched upon in the Victorian and NSW studies. In Tasmania, the discussions are broadly similar but without any accompanying discussion in newspapers or policy journals. The main strategic question that has generated conflict is whether or not the SHA should pursue stock transfers in order to generate resources via Commonwealth Rental Assistance payments. Those in favour of stock transfer generally view it as a pragmatic innovation to attract more resources, while those opposed to stock transfers raise concerns about tenants' statutory rights and their security.

There is more agreement amongst key actors about three of the key strategic issues. First, that stock transfers do not in themselves result in an increase in supply of social housing; second, that there is limited capacity within the Community Housing Association sector to manage more transferred stock; and third, that significant stock transfer would result in a diminution of the SHA's role as a direct provider of services. These three key strategic issues are discussed in turn.

Generating additional income. The continued interest in further stock transfer arrangements is predicated on the assumption that the Commonwealth government will continue to reduce subsidies for public housing and instead resource low-cost housing either though subsidies to homeowners (first time buyers grants) or individual subsidies to low-income households through Commonwealth rental assistance payments. In this political context, it is acknowledged that stock transfers could be a vehicle to capture additional funds, as tenants in housing association stock are eligible for Commonwealth Rental Assistance. As one interviewee from within the Housing Authority acknowledged "community housing can actually leverage additional dollars, it can bring in additional services because of the capacity to ( $\mathrm{sic}$ ) Commonwealth Rent Assistance, so there's an official kind of shift of the dollars from the Commonwealth to the State". Another interviewee adopted a similar perspective: 
Fundamentally, the Commonwealth Government prefers to allocate recurrent payments to clients rather than to SHAs. They'd rather put the money into client's pockets so that they can then go and choose the provider and so on and they know one of the things is that there has been a consistent decline in funds via Commonwealth/State Housing Agreement.

One government interviewee was very clear about the problems of not transferring stock:

by not transferring out stock then you are not able to take advantage of the factors that are out there like Commonwealth Rent Assistance.... we expect that this CHSA may well be the last capital funding bucket for states and we expect by that point that the Commonwealth will provide most of its assistance through a recurrent rental payment.

Alongside the pragmatic rationale for additional resources is a set of other claims made primarily by the 'not for profit' sector that small community run housing associations are better able to provide a responsive management service than large SHAs. Stock transfers, it is argued, can provide a fast track route to increasing the size and viability of the community housing sector, so long as the stock that is transferred is of a good standard and not simply hard to let properties.

It was apparent from the focus group discussion, that tenants residing in stock that had been transferred were overwhelmingly supportive of their community housing association landlord. Interviewees, attending the focus group, suggested that their rents were both affordable (maximum rent is \$100) and the service provided by Red Shield was responsive and user-friendly. "I'd like to say if you've got problems Red Shield will help you out as much as they can." Interviewees felt that they had more autonomy as a community housing resident as the following quote makes clear: "well you can do things in community housing that you couldn't do with [public] housing. Like repaint the place, but with [public] housing you don't have as many rights." The endorsement of tenants for the services provided is indicative of the high level of satisfaction amongst community housing tenants in Tasmania. ${ }^{4}$ However, the optimism of tenant and community activists stands in direct contrast with a number of actors within the government and peak body sectors. One interviewee's comments encapsulated a general concern with stock transfers "my biggest problem with stock transfer is that it doesn't actually increase affordable housing because all you're doing is changing the management style".

Limited capacity of the 'not for profit' sector. In the case of Tasmania, the biggest obstacle to extending the stock transfer process is the perceived lack of capacity within the 'not for profit' sector. As one community housing sector interviewee pointed out "we've got a very small sector, so we haven't necessarily got the resources, so part of the stock transfer concept was to try and give it a bit of a helping hand, to try and develop an alternative provider". Comments such as this were articulated by actors working for the 'not for profit' sector as well as those working for the SHA. It can be discerned from recent UK literature (Malpass \& Mullins, 2002) that if stock transfers are to go ahead in Tasmania, it will be prudent for the current SHA affordable housing strategy to provide 
practical measures to enhance the infrastructure and generate resources for community housing agencies to extend their role. One of the most interesting explanations to account for the State government's willingness to resource community housing was provided by one interviewee working in the SHA, "it's all about competition, ... there was a lot of criticism then about ineffective large bureaucracies, so encouraging the community sector to manage housing fitted neatly with this perspective". This viewpoint conforms closely to some of the ideological arguments adopted from a neo-liberal perspective; that is that the break up of monolithic service providers and the introduction of competition will result in improved delivery outcomes.

Diminution of the State government's role. However, in spite of the commitment of the SHA to seek ways of supporting the community sector, interviewees from the 'not for profit' sector were less sanguine about the chances of further stock transfer. One interviewee suggested that in spite of stated policy objectives "there is resistance from some within the housing authority sector because predominately they don't want their good properties to get transferred or want large numbers of stock to be transferred because then they won't have a job". However, another interviewee took a contrary view, suggesting instead that it was in the State government's political interest to divulge itself of responsibility for low-cost housing:

my cynical view is that with a community tenancy you shift the responsibility from the government to the private sector and so therefore issues such as evictions, conditions of properties, vacancies, perceived non-action on the waiting list and seeing properties vacant and all the rest of it would no longer be the Government's concern. I think it is in the Government's interest to pass the responsibilities to others to be able to say "Oh well we no longer manage those properties. You need to go to Colony or Red Shield to sort those things out". A large community housing sector would take the heat off the Government.

It can be discerned from the divergent views that housing policy in Tasmania is at a critical juncture. While there is no existing policy in place to pursue a new stock transfer program, the discussions taking place around the affordable housing strategy indicate that policies to diversify the public housing stock in Tasmania are being actively considered and that stock transfers are almost certain to form an integral component of future strategy.

\section{Conclusions}

The focus group discussions with tenants, interviews with key policy actors in government and 'not for profit' housing sectors provide a rich source of information. It highlights in microcosm some of the key tensions about the role of welfare and debates about appropriate models for service delivery. A number of important issues can be discerned from the three case studies in Victoria, NSW and Tasmania.

First, the public-private mix appropriate for social housing remains deeply contested. At present in Australia, the discourse of 'community' has drawn increasing political support and expressions of this support were evident from the responses of many of the interviewees. In some sense, this is not unexpected 
for as Gilbert (2002, p. 163) has argued: community models for "service delivery respond to the anti-statist, market-orientated ideology of the Right; to the citizens' empowerment objectives of the Left; and most of all to the modern infatuation with civil society on both sides of the political spectrum".

Second, it should come as no surprise that community housing is seen as preferable by many tenants. A feature of contemporary policy making is that whilst private agencies are heralded as innovative and responsive to consumer needs, public sector institutions are often portrayed as unwieldy and remote. However, it is also true that, up to the present, there has been no fair basis for comparison between tenant experiences in public and community housing, as a number of study participants from the public housing authorities were keen to point out.

Third, the prospect of large-scale stock transfer in each state remains a very controversial issue. A number of policy actors interviewed for this project (particularly in Victoria) wanted to move away from the polarised positions that have characterised the policy process so far. There was an expressed desire to establish some common interests. In moving towards this goal, part of the controversy over stock transfers needs to be seen within a broader debate about the role of governments and their direct responsibility to provide affordable, secure housing. Some policy actors in each of the three states viewed stock transfers as a form of privatisation and questioned the effectiveness and efficiency of this strategy, while others claimed that the community sector has distinct benefits and needs to be regarded differently from private interests because of an explicit non-profit focus. This micro debate reflects broader changes in the mixed economy of welfare, which are taking place in other areas of social policy, such as employment services. On this point, Little (2002) argues that when we examine contemporary debates about community-based options we need to ask its advocates to stop providing answers and to start recognising the questions.

Fourth, both tenant advocates and community housing providers/peak organisations want to see clarity and some clear political direction on these issues in the future. There is a sense in which the policy process has drifted. Tenant advocates in both NSW and Victoria in particular wanted to see the establishment of a clear policy framework for why stock transfers should take place, starting from the position of mandated tenant outcomes in an agreed regulatory framework that contains meaningful guarantees and reporting requirements.

Fifth, it is clear that at the policy level, the most pressing priority is the need to increase the financial viability of the social housing sector and an expectation that stock transfer might be one of the means to achieve this viability. Whilst others may see stock transfer as undesirable it is this financial imperative which appears to be the main driver for policy innovation in this area, yet it remains unclear how it is expected that large-scale stock will advance this cause.

Uncertainty about the financing of social housing provision is the primary factor that can best explain the emerging debates and contestation about the role of stock transfer in all three states. Continued uncertainty is likely to prolong contestation as well as undermine SHAs' efforts to develop coherent policies to offset the decline in Commonwealth funding for public housing provision. 


\section{Notes}

1. The Australian Institute of Health defines community housing dwellings and Welfare (2003) as those funded (either capital or recurrently) through the CSHA; where tenancy management functions are undertaken by a community provider or local government; provides medium to long-term housing. It specifically excludes dwellings funded under the Crisis Accommodation Program.

2. There is very little public information available on the type of projects funded and the outcomes achieved from this investment (Community Housing Federation of Victoria, 2003).

3. This expectation is premised on the basis that tenants who reside in community housing properties can be charged higher rent than those in public housing and therefore are able to access Commonwealth Rental Assistance.

4. In a national survey of community housing tenants, Tasmania has the highest level of tenant satisfaction (88 per cent) in Australia (8 per cent higher than the national average) (Donovan Research, 2001, pp. 8-9; Donoghue \& Tranter, 2003).

\section{References}

Australia's Welfare (Canberra: Australian Institute of Health and Welfare). Available at http:// www.aihw.gov.au/publications/index.cfm/title9629

Bisset, H. (2000) Social Housing: Building a New Foundation, Social Housing Innovations Project, Consultants Report (Melbourne: Office of Housing, Department of Human Services).

Cahill, M. (1994) The New Social Policy (Oxford: Blackwell).

Clapham, D. \& Kintrea, K. (1994) Community ownership and the break-up of council housing in Britain, Journal of Social Policy, 23(2), pp. 219-245.

Community Housing Federation of Victoria (2003) CHFV News (Melbourne: CHFV).

Darcy, M. (1996) Community Housing: The Consumer Perspective, National Shelter Research Paper No. 2 (Canberra: National Shelter).

Darcy, M. (1999) The discourse of community and the re-invention of social housing in Australia, Urban Studies, 36(1), pp. 13-26.

Darcy, M. \& Stringfellow, J. (2001) Tenants' Choice or Hobson's Choice: A Study of the Transfer of Tenanted Dwellings from Public Housing to Community Housing in NSW (Sydney: Urban Frontiers Program University of Western Sydney).

Donavan Research (2001) Survey shows that tenants are happy with community housing, Housing Matters, 9(5), pp. 1-9.

Donoghue, J. (2001) Red Shield Housing Association (Tas.). Paper prepared for the TSA Social Housing Seminar 2001.

Donoghue, J. \& Tranter, B. (2003) Community Housing in Tasmania: The Demand for Stock Transfers, Occasional Paper (Hobart: School of Sociology, University of Tasmania).

Family and Community Services (FACS), Commonwealth Department of (2003) Commonwealth State Housing Agreement 2003. Available at http://www.facs.gov.au/internet/facsinternet.nsf/AboutFaCS/programs/house-csha.htm

Farrar, A., Barbato, C. \& Phibbs, P. (2003) How Does Community Housing Help Strengthen Communities? Final Report (Melbourne: AHURI).

Gilbert, N. (2002) Transformation of the Welfare State: The Silent Surrender of Public Responsibility (Oxford: Oxford University Press).

Housing for the Aged Action Group (HAAG) (2001) Campaign Against the Social Housing Innovations Report (S.H.I.P). Available at http://www.oldertenants.org.au/SHIPreport2001.htm

Industry Commission (1993) Public Housing: Draft Report (Canberra: AGPS).

Jacobs, K. (1999) The Dynamics of Local Housing Policy (Aldershot: Ashgate Press).

Little, A. (2002) The Politics of Community: Theory and Practice (Edinburgh: Edinburgh University Press).

Malpass, P. \& Mullins, D. (2002) Local authority housing stock transfer in the UK: from local initiative to national policy, Housing Studies, 17(4), pp. 673-686.

Mant, J. (1992) Inquiry into the Department of Housing: Report of Commissioner John Mant (Sydney: Department of Housing).

Murie, A. (1995) Tenants' choices: sales, transfers and trusts, in: R. Pinto (Ed.) Developments in Housing Management and Ownership (Manchester: Manchester University Press).

National Audit Office (2001) Regulating the Housing Associations' Management of Financial Risk (London: National Audit Office). Available at www.nao.gov.uk 
National Housing Strategy (1992) Agenda for Action, Issues Paper No. 7 (Canberra: AGPS).

NSW Department of Housing (1999) Directions for Housing Assistance Beyond 2000, Background Paper (Sydney: NSW Department of Housing).

NSW Department of Housing and Office of Community Housing (1997) Transfer Program Protocol (Sydney: NSW Department of Housing and Office of Community Housing).

Productivity Commission (2004) Report on Government Services (Melbourne: Productivity Commission).

Steering Committee for the Review of Commonwealth State Service Provision (2000) Report on Government Services (Canberra: AusInfo). 
